\title{
Imágenes Landsat TM y modelo digital de elevación para la identificación de lineamientos y mapeo litológico en Punta Mita (México)
}

\author{
Thamara Fernández de la Vega-Márquez ${ }^{1, *}$, Rosa María Prol-Ledesma² \\ ${ }^{1}$ Facultad de Filosofía y Letras, Universidad Nacional Autónoma de México, Ciudad Universitaria, 04510, \\ México, D.F. \\ 2 Instituto de Geofísica, Depto. Recursos Naturales, Universidad Nacional Autónoma de México, Ciudad \\ Universitaria, 04510, México, D.F. \\ *thamara_geo@yahoo.com.mx
}

\begin{abstract}
Resumen
En la zona de Punta Mita se ha reportado recientemente una intensa actividad hidrotermal, la cual se manifiesta como descargas de agua caliente y gases en el fondo marino. Para explicar dicha actividad se han hecho estudios del contexto tectónico y geológico que pueden tener influencia en la presencia de esa actividad. Por esto, mediante el uso de un Modelo Digital del Terreno e imágenes Landsat Thematic Mapper en la zona de Punta Mita se hizo una identificación de las estructuras geológicas principales y una diferenciación litológica que permita hacer una comparación con datos reportados anteriormente, trabajo de campo y el mapa geológico de la zona. El uso conjunto de técnicas de realce digital como los filtros direccionales y el Análisis Selectivo de Componentes Principales, así como el análisis morfo-hidrogeológico en el que se incluyó la identificación del patrón de drenaje, fueron de utilidad para obtener información complementaria que en este caso facilita la elaboración de un mapa geológico a detalle de Punta Mita. Se determinaron los principales sistemas de lineamientos con dirección $\mathrm{N} 0^{\circ}-10^{\circ} \mathrm{E} ; \mathrm{N} 40^{\circ}-50^{\circ} \mathrm{E} ; \mathrm{N} 70^{\circ}-80^{\circ}$ E y los $\mathrm{N} 40^{\circ}-60^{\circ} \mathrm{W}$, el segundo de los cuales se encuentra relacionado con la descarga de fluidos hidrotermales en el fondo marino.
\end{abstract}

Palabras clave: Realce digital, análisis selectivo de componentes principales, Bahía de Banderas, bloque Jalisco

\begin{abstract}
Intense hydrothermal activity has been reported recently in the Punta Mita area. This activity occurs as focused and diffuse discharge of gas and hot water from the ocean bottom. In order to explain the presence of this geothermal activity, the tectonic and geologic characteristics of the area have been studied. As part of these studies, the digital elevation model and multispectral images of Punta Mita were processed to identify the main geological structures. The results obtained from the DEM and image processing were compared with the field truth and previously reported geological maps. The use of directional filters and principal components, as well as the morpho-hydrogeologic analysis of the drainage pattern, provided useful information to construct a detailed geological map of Punta Mita. The lineaments are arranged in four systems, according to their abundance: $N 0^{\circ}-10^{\circ} \mathrm{E} ; \mathrm{N} 40^{\circ}-50^{\circ} \mathrm{E} ; \mathrm{N} 70^{\circ}-80^{\circ}$ $E$ and $N 40^{\circ}-60^{\circ} \mathrm{W}$, the second one is the one related with the submarine hydrothermal discharge and coincides with the emplacement of basaltic dykes in the area.
\end{abstract}

Keywords: Digital enhancement, principal components, Banderas Bay, Jalisco block 


\section{Introducción}

La presencia de actividad hidrotermal submarina cercana a las costas es un fenómeno generalmente relacionado con algún tipo de actividad volcánica reciente; sin embargo en el área de Punta Mita no se tiene reportada este tipo de actividad. Los estudios de la geoquímica del agua termal indican la predominancia de agua meteórica y la posibilidad de calentamiento debido únicamente a la circulación profunda de ésta, por lo cual es de gran importancia la definición de las estructuras principales de la zona que permitan la penetración y descarga del agua termal.

El área de estudio está localizada en la parte norte de la bahía de Banderas. A 400 de metros de la costa se descubrió la presencia de ventilas hidrotermales localizadas a $20^{\circ} 45.15^{\prime}$ de latitud norte y $105^{\circ} 28.87^{\prime}$ de longitud oeste; éstas se encuentran emplazadas en basaltos y a una profundidad de aproximadamente $11 \mathrm{~m}$ (Núñez-Cornú et al., 2000). Esta es una de las pocas localidades conocidas en la costa del Pacífico mexicano, donde se presenta este fenómeno tan cercano a la costa y a tan poca profundidad. Para conocer las características que las originaron es necesario definir las estructuras principales relacionadas con el transporte de los fluidos termales y su relación con la tectónica de la zona, con la finalidad de definir los procesos que generan el calentamiento y transporte de los fluidos. El objetivo de este trabajo es mejorar la información geológica de la zona cercana a las ventilas, en el que se presenten la litología y los lineamientos principales que reflejan el contexto tectónico predominante en la zona de Punta Mita, ya que el mapa con que se contaba antes de este trabajo es demasiado general (Figura 1) e insuficiente para realizar un modelo conceptual del sistema hidrotermal submarino.

\section{Geología regional}

Esta es una zona para la cual se han realizado numerosos estudios de tipo regional, así como diversos trabajos que involucran a las zonas circundantes, como son $\mathrm{La}$ Sierra Madre Occidental, el Golfo de baja California y la parte Oeste del Cinturón Volcánico Mexicano (CVM). Algunos autores (Gastil et al., 1979; Helenes y Carreño 1999; Ferrari et al., 1999, 2000; Schaaf et al., 2000) indican que es posible correlacionar esta localidad con la parte sur de la península de Baja California y por lo tanto con los procesos tectónicos que dieron origen a la apertura del Golfo de California. De acuerdo con las provincias geológicas establecidas, esta área se encuentra en el bloque Jalisco, tiene una edad mesozoica y el basamento es de origen plutónico, que se formó en un ambiente geotectónico de raíz de arco (Sedlock et al., 1993; Figura 1). El bloque Jalisco se encuentra delimitado hacia el Oeste por la trinchera Meso-Americana, hacia el Este por el rift de Colima, y hacia el norte por la zona de rift Tepic-Zacalco. Este rift incluye un arco volcánico calci-alcalino activo, el cual es el límite hacia el sur del vulcanismo silícico de la Sierra Madre
Occidental (Wallace et al., 1992). Este bloque muestra las etapas iniciales del rompimiento que dio como resultado la separación de la península de Baja California del resto del continente. En la zona se tienen dos sistemas principales de fallas (de $35^{\circ}-45^{\circ}$ ) que presentan un salto de aproximadamente $600 \mathrm{~m}$ (Ferrari et al., 1994), así como un complejo de cuerpos intrusivos conocido como el batolito de Puerto Vallarta. El batolito está formado por cuerpos de dioritas, granitos y tonalitas, los cuales presentan edades de $85 \mathrm{Ma}$ (Schaaf, 1990). Las estructuras presentes nos definen lo que se conoce como el graben de Puerto Vallarta. Los estudios que se han realizado indican que es posible correlacionar a través de la edad y de las características isotópicas a los batolitos de Puerto Vallarta y el de los Cabos (Schaaf et al., 2000). Por lo anterior se puede inferir que la parte sur de Baja California se encontraba localizada a lo largo de la costa norte de Punta Mita antes del desprendimiento de la península y que las fallas que dieron origen al graben de Puerto Vallarta se habrían formado durante la separación de Baja California de la placa Norteamericana, proceso que posiblemente se presentó entre el Mioceno tardío y el Plioceno temprano (Ferrari et al., 1994).

La relación de la geología del oeste de Nayarit y el noroeste de Jalisco está determinada por varios afloramientos. Al noreste del estado de Nayarit se encuentra expuesta la Sierra Madre Occidental, presentando una intercalación de rocas volcánicas de carácter silícico con depósitos fluviales. Estos últimos pueden ser correlacionados con otros similares que afloran entre Mazatlán y Durango (Gastil et al., 1979). Hacia el suroeste del río Santiago, las rocas que pertenecen a la Sierra Madre Occidental se encuentran casi completamente cubiertas por las secuencias del Cinturón Volcánico Mexicano. En esta zona, la actividad volcánica está representada por afloramientos al norte de Tepic (Ferrari et al., 2000), los cuales están alineados aproximadamente con una dirección $\mathrm{N} 45^{\circ} \mathrm{W}$ y se encuentran descansando sobre un terreno volcánico más amplio. A este terreno le han determinado edades de 21 a 8 Ma y representa una actividad anterior a la del CVM (Ferrari et al., 2000).

Este terreno puede dividirse litológicamente en dos secuencias, algunos basaltos y riolitas con edades de 8 a $10 \mathrm{Ma}$ (Gastil et al., 1979) que se localizan en la parte noroeste y a lo largo de la costa de Nayarit, la cual se puede correlacionar con la litología presente en el área de Punta Mita. Existen otras rocas volcánicas con edades de 21 a 14 Ma (Gastil et al., 1979) que pueden ser correlacionadas con algunas rocas de edades similares en Baja California y Sonora. Los basaltos con edades de $10 \mathrm{Ma}$ se presentan al noroeste de Tepic y a lo largo de la costa en Punta Raza y Punta Mita (Ferrari et al., 2000). Estos basaltos se encuentran intercalados con depósitos de areniscas de origen volcánico, las cuales presentan foraminíferos (Gastil et al., 1979). Se piensa que estas rocas fueron depositadas en un embalse localizado al sur del proto-Golfo de California. Estas rocas sedimentarias pueden ser correlacionadas con 


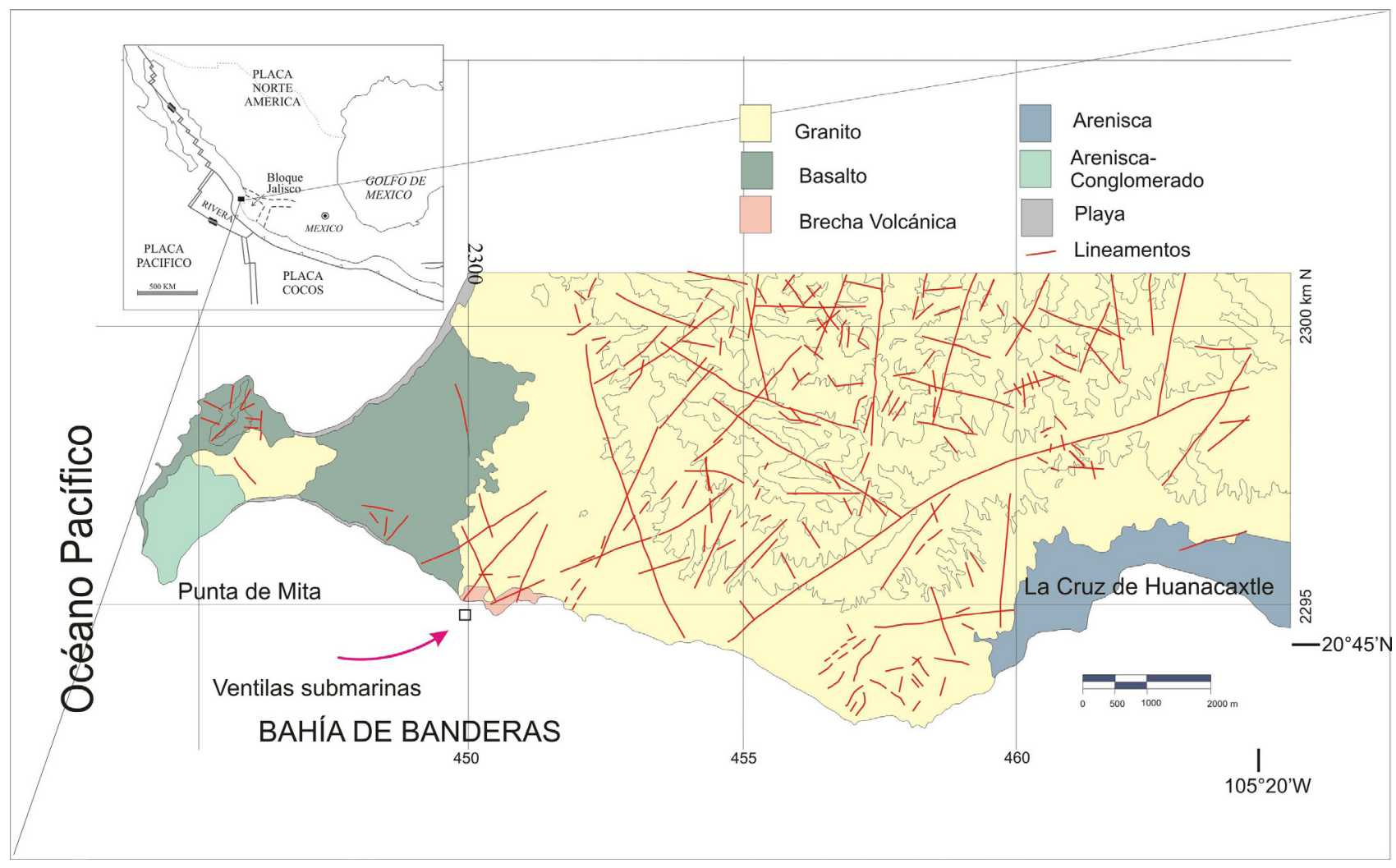

Figura 1. Geología de la zona antes de este estudio, se incluye la localización de las manifestaciones hidrotermales submarinas (A partir de Núñez-Cornú et al., 2000).

otros depósitos en las Islas Marías (Helenes y Carreño, 1999), lo cual indica que en esta área se presentó un ciclo de transgresiones y regresiones marinas que comenzó en el Mioceno y culminaron en el Plioceno. Se considera que las rocas volcánicas del este de Nayarit representan una etapa temprana del vulcanismo que posteriormente daría lugar a la formación del CVM (Ferrari et al., 2000).

Las estructuras volcánicas más comunes en esta región son mesetas, flujos de lava en fisuras y volcanes monogenéticos. Todas estas estructuras presentan edades de entre 11.2 y 8.7 Ma y se concentran al noreste del cinturón volcánico más reciente que presenta edades un poco menores de 11 a 8.5 Ma y de 9.6 a 8.1 Ma (Ferrari et al., 2000). Esto puede indicar la migración de la actividad volcánica hacia el sureste, lo cual es una característica del CVM y por lo tanto se supone que existe cierta influencia de éste en la zona a estudiar que se encuentra hacia el sur de estas estructuras.

De acuerdo con algunos estudios, las rocas ígneas máficas que afloran hacia el oeste de Nayarit (con una edad aproximada de $10 \mathrm{Ma}$ ) varían en composición de basaltos a andesitas basálticas (Ferrari et al., 2000). Las lavas de la planicie de Nayarit pertenecen a la serie calci-alcalina; después de este episodio, se han depositado conglomerados que se encuentran afectados por fallas y esto indica que la zona de estudio presenta una tectónica activa de tipo extensional que genera los canales de flujo para la actividad hidrotermal.

\subsection{Geología de la localidad de Punta Mita, Nayarit}

En la zona de Punta Mita se encontró una relación geológica compleja que refleja los procesos que se han desarrollado aquí, los cuales están vinculados con los procesos de apertura del Golfo de California y con las primeras etapas de formación del CVM (Ferrari et al., 1994). El basamento está formado de rocas metamórficas, principalmente un gneiss cuarzo-feldespático y un gneiss calcáreo, los cuales se interpretan como pertenecientes al Paleozoico debido a su relación con el batolito de Puerto Vallarta (Schaaf et al., 1993). Las relaciones geológicas que presenta éste con respecto a las demás rocas de la localidad no son muy claras, debido a los procesos tectónicos a los cuales fue sometido.

Por encima de este basamento, se observaron mármol y un intrusivo de composición granodiorítica. Se considera que estas unidades son de la parte baja del Cretácico debido a su posición estratigráfica y el intrusivo puede relacionarse con la actividad del norte del batolito de Puerto Vallarta con una edad de $99 \pm 4 \mathrm{Ma}$ (Schaaf et al., 1993). Hacia el noreste de la localidad se encontró un cuerpo milonítico que puede estar atravesando a todas las secuencias anteriormente mencionadas, el cual se localiza a una latitud de $20^{\circ} 48^{\prime} 52.0^{\prime \prime} \mathrm{N}$ y longitud $105^{\circ} 27^{\prime} 19.1^{\prime}$ ' W.

Después de este periodo de actividad, que se interpreta duró del Paleozoico superior hasta el final del Cretácico, 
se presentó el depósito de cuerpos delgados de areniscas y limolitas, las cuales pertenecen al Terciario tardío. Posteriormente comenzó el proceso de actividad magmática que observamos en la actualidad. Es durante la parte inferior del Terciario que se presentan flujos de lava de composición basáltica, así como una ignimbrita de composición riolítica.

En la actualidad, los basaltos se presentan en forma de terrazas de erosión por oleaje (Figura 2). Esto indica que se ha presentado una regresión en el nivel del mar o bien que el bloque de la corteza donde se encuentran ha sufrido un proceso de levantamiento, el cual se debe haber desarrollado rápidamente (Ramírez, 2002). Algunos flujos de lava presentan estructuras de lavas almohadilladas. También podemos encontrar algunos diques de composición basáltica con dirección NE e inclinados hacia el NW y depósitos piroclásticos de composición basáltica con una matriz compuesta de microcristales de plagioclasa. Estos cuerpos se encuentran inter-estratificados con areniscas y limolitas calcáreas, las cuales contienen microfósiles pertenecientes al Mioceno superior (Helenes y Carreño, 1999). Esto nos indica que el proceso de sedimentación y la actividad ígnea que se presentó en la zona hace aproximadamente $10 \mathrm{Ma}$ fueron contemporáneas en algún periodo. También nos indica que se presentó un cambio en el tipo de sedimentación y por lo tanto en las condiciones de la cuenca de depósito.

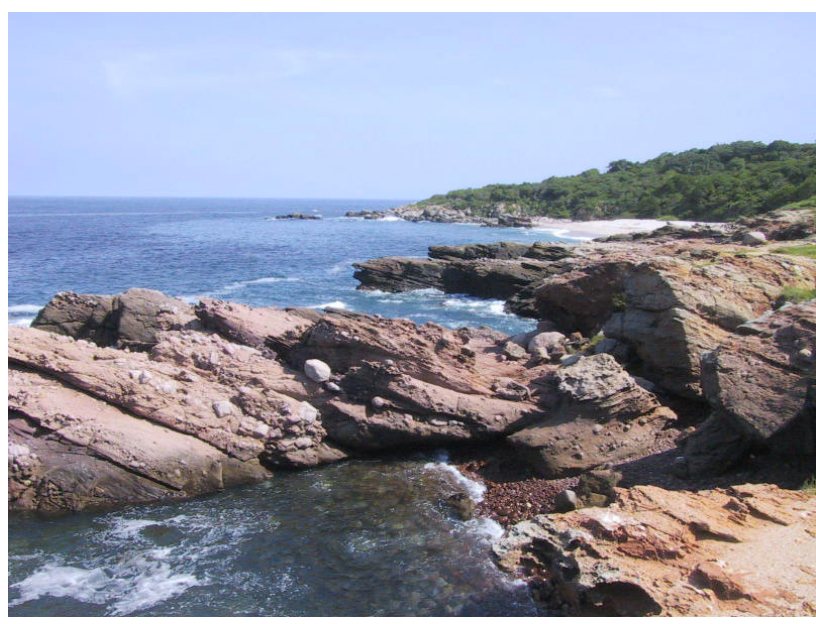

Figura 2. Coladas de basalto que forman terrazas de erosión en las playas de Punta Mita.

Al concluir este periodo de actividad, se registra el depósito de conglomerados que presentan fragmentos de basalto, riolita y granito, lo cual indica que su formación es posterior a este periodo de actividad. Por último, encontramos algunos sedimentos no consolidados, con partículas del tamaño de arenas, que se encuentran cubriendo a toda la secuencia anterior y que representan los depósitos más recientes del área de estudio.
Las características estructurales y los indicadores de movimiento en la localidad son principalmente dos familias de fallas, las cuales tienen dirección predominantemente hacia el noreste, se cortan entre sí y presentan una apertura muy pequeña de aproximadamente un centímetro. Algunas de estas fallas están rellenas de zeolitas producto de la depositación directa a partir de un fluido hidrotermal. Por otra parte, tenemos la presencia de diques, que nos indican zonas de debilidad a través de las cuales se presentó el flujo del magma. Los desplazamientos de las fallas son generalmente pequeños y se encuentran cortando los depósitos piroclásticos, de tal manera que no ha sido posible caracterizarlas; sin embargo, su importancia radica en que aumentan localmente la permeabilidad de las rocas. La mayoría de las fallas mapeadas en campo presentan una dirección NE y echado hacia el NW y algunas otras tienen dirección NW y echado hacia el NE (Prol-Ledesma et al., 2003). Las rocas ígneas descansan sobre los estratos de areniscas y limolitas que presentan rumbos aproximadamente paralelos a la costa actual y se inclinan en dirección hacia el mar, lo cual indica que aunque no han sido afectados en su posición, sí han sufrido un proceso de basculamiento.

\section{Metodología}

Con el objetivo de identificar los principales conjuntos de lineamientos y determinar los contactos geológicos en la zona de estudio se utilizaron cuatro diferentes clases de datos que se procesaron para enfatizar los rasgos geológicos espaciales y espectrales del área en estudio: Estos datos incluyeron mapas topográficos y geológicos escala 1:50,000 de Punta Mita, imágenes de las 6 bandas espectrales no térmicas del Landsat 5 Thematic Mapper, el modelo digital de elevación y los datos recopilados durante la verificación en campo.

La identificación de las estructuras se realizó con el mapeo de lineamientos utilizando imágenes de satélite y el modelo digital del terreno (Wester y Lundén, 1996; Mustard y Sunshine, 1999; Zumsprekel y Prinz, 2000) y los resultados fueron posteriormente validados en varias etapas de verificación en campo.

Con los mapas topográfico y geológico se hizo un análisis morfohidrológico para el reconocimiento del patrón de drenaje, el cual es uno de los factores más importantes que contribuyen para la identificación de lineamientos en un área, ya que refleja muchas de las características predominantes como la pendiente, el tipo de material y también el sistema de fracturamiento. Por lo tanto el primer paso en la evaluación de los lineamientos es reconocer el sistema de drenaje de la región (Süzen y Toprak, 1998).

Además del análisis morfohidrológico, se empleó el realce espacial, que en una primera etapa consistió en el Análisis de Componentes Principales de las imágenes TM y la posterior aplicación de varios filtros direccionales a la 
imagen de la Componente Principal 1 y la aplicación de un algoritmo de iluminación artificial al Modelo Digital de Elevación. Una de las aplicaciones más comunes de los filtros direccionales es precisamente el realce de rasgos lineales sutiles o el mapeo de lineamientos y rasgos geomorfológicos, los cuales no son claramente visibles directamente sobre las imágenes o sobre el Modelo de Elevación no procesado. En el caso de este trabajo se seleccionaron filtros direccionales con base en las direcciones de una parte de los lineamientos previamente reportados por Núñez-Cornú et al. (2000), y los datos de campo de la zona (Prol-Ledesma et al., 2003). Los lineamientos identificados se graficaron en un diagrama de rosa, pero en este caso decidimos que la frecuencia solamente no proporcionaba suficiente información acerca de la importancia de estos lineamientos, por lo cual en los diagramas se incluyó no solamente la suma del número de lineamientos en cada dirección, sino que se tomó también en cuenta la longitud de los lineamientos. De esta forma, el diagrama nos proporciona información acerca de la importancia de las estructuras.

Una vez hecha la identificación de lineamientos, el realce espectral permitió caracterizar, mediante el Análisis Selectivo de Componentes Principales (ASCP) (Chávez y Kwarteng, 1989), las unidades correspondientes a la litolo- gía superficial para producir un mapa geológico que mostrara así la relación entre los lineamientos y la litología. La verificación en campo se limitó a un área de $158 \mathrm{~km}^{2}$ desde el pueblo Cruz de Huanacaxtle hasta Punta Mita en la parte más occidental del norte de la Bahía de Banderas, y hasta el Cerro Pátzcuaro hacia el noreste de Punta Mita.

\section{Análisis morfohidrológico}

Se estableció como límite para el reconocimiento del drenaje la porción norte de Punta Sayulita al norte y Bucerías al este. Sobre la carta topográfica escala 1:50,000 se efectuó el reconocimiento del patrón de drenaje para reconocer la extensión y localización de los materiales que tienen diferencias significativas, así como la localización de los lineamientos (Figura 3), ya que el flujo superficial es controlado por el tipo de material y por zonas de debilidad litológica y estructural. De este modo fue posible identificar cuatro tipos de drenaje:

Rectangular: Generalmente se presenta en rocas metamórficas, como pizarras, esquistos y gneiss. Se identificó este tipo de drenaje en la parte central de Punta Mita (área 2 en Figura 3).

Paralelo: Se localizó desde la carretera hacia Bucerías

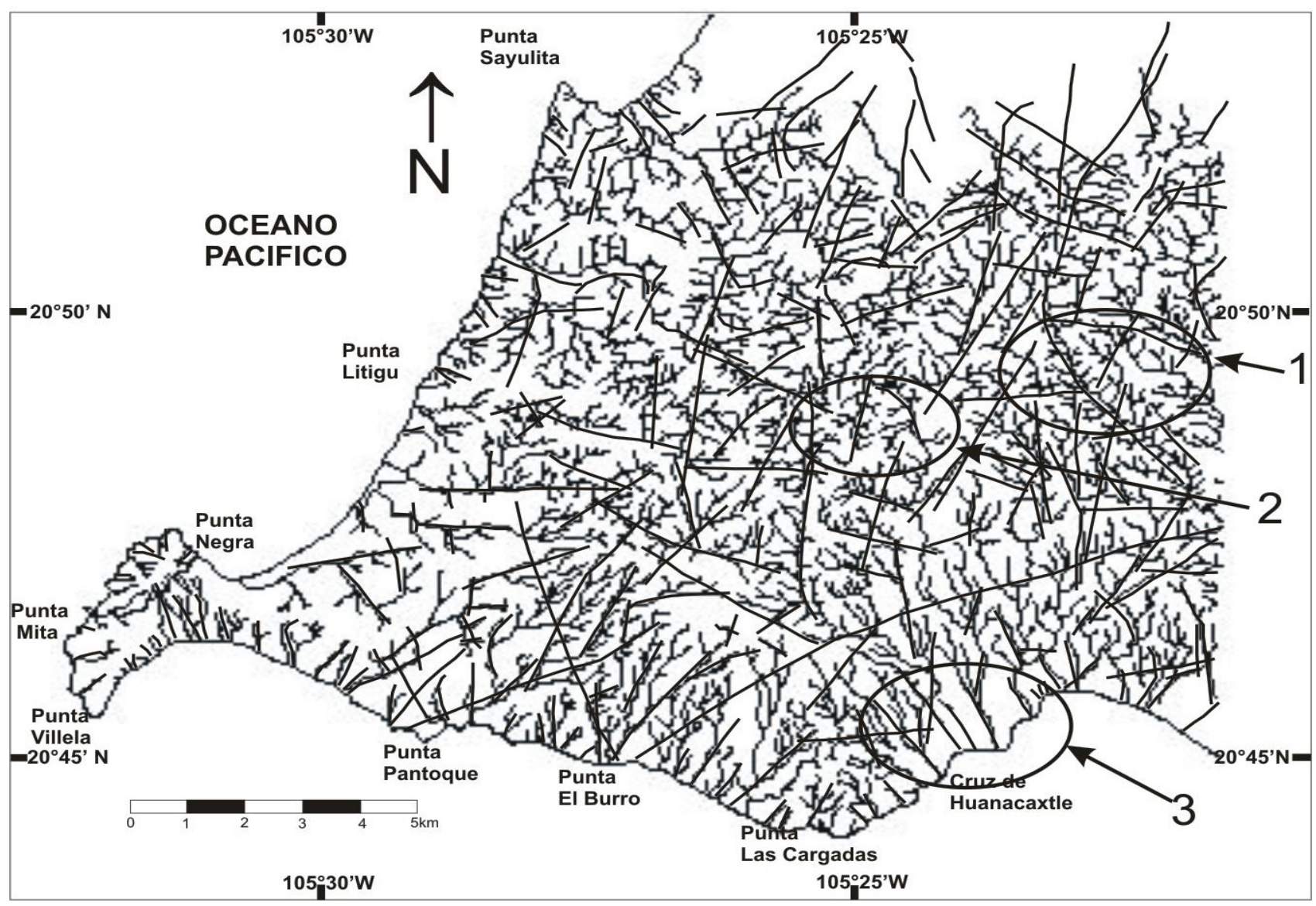

Figura 3. Mapa del patrón de drenaje y los lineamientos identificados en la zona de estudio. Los tipos de drenaje descritos en el texto: 1 - dendrítico, 2 - rectangular, 3 - paralelo, 4 - angular. 
hasta Punta el Burro sobre la costa (área 3 en Figura 3).

Dendrítico: Este tipo de drenaje predomina en rocas sedimentarias homogéneas y en rocas graníticas. Este tipo de drenaje es el que predomina en la zona de Punta Mita (área 1 en Figura 3).

Angular: Se restringe a la zona desde Punta Negra hasta Higuera Blanca (área 4 en Figura 3).

El siguiente paso del procesado fue identificar y mapear los lineamientos a partir del patrón de drenaje (Figura 3 ), los cuales fueron contados y segmentados para elaborar un primer diagrama de rosa (Figura 4) que se comparó con el diagrama obtenido con el realce espacial aplicado al Modelo Digital de Elevación.

En total se contabilizaron 112 lineamientos que mostraron orientaciones preferenciales entre los $\mathrm{N} 0^{\circ}-10^{\circ} \mathrm{E} ; \mathrm{N}$ $30^{\circ}-40^{\circ}$ E y N $80^{\circ}-90^{\circ}$ E (Figura 4).

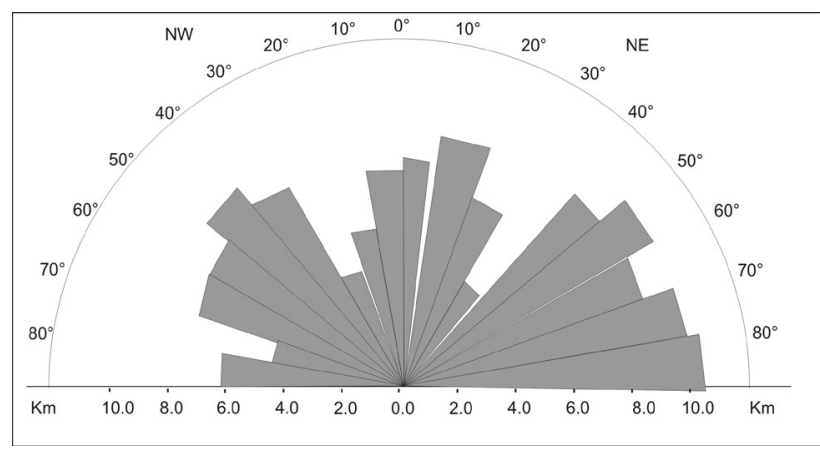

Figura 4. Diagrama de rosa obtenido a partir de los lineamientos identificados en el Análisis Morfológico. (En el diagrama se han graficado los lineamientos en escala de longitud en lugar de frecuencia). Las direcciones preferenciales están entre los $\mathrm{N} 40^{\circ}$ y $50^{\circ} \mathrm{E} ; \mathrm{N} 0^{\circ}-10^{\circ}$ E y $\mathrm{N} 80^{\circ}-90^{\circ} \mathrm{E}$.

\section{Resultados del realce espacial}

Para el realce espacial se siguieron los criterios que se refieren por Ruíz-Armenta y Prol-Ledesma (1995) para la identificación de los lineamientos. Estos rasgos geomorfológicos se examinaron para comparar posteriormente los resultados obtenidos tanto en el análisis morfológico como en el realce espacial.

El realce de lineamientos se hizo mediante filtros direccionales. En este caso se obtuvieron buenos resultados con los filtros direccionales de Prewitt, los cuales se sobrepusieron para lograr identificar el mayor número de lineamientos en todas las direcciones.

Los lineamientos identificados se digitalizaron sobre el Modelo de Elevación (MDE) (Figura 5). Con este método se contabilizaron 151 lineamientos, con los cuales se elaboró un diagrama de rosa (Figura 6) en el que se observó que las mayores frecuencias de lineamientos se encuentran entre las $\mathrm{N} 0^{\circ}-10^{\circ} \mathrm{E} ; \mathrm{N} 30^{\circ}-40^{\circ} \mathrm{E}$ y $\mathrm{N} 70^{\circ}-80^{\circ} \mathrm{E}$, coincidiendo las dos primeras orientaciones, y muy cercanos a la tercera orientación, identificada con los resultados obtenidos a partir del patrón de drenaje.

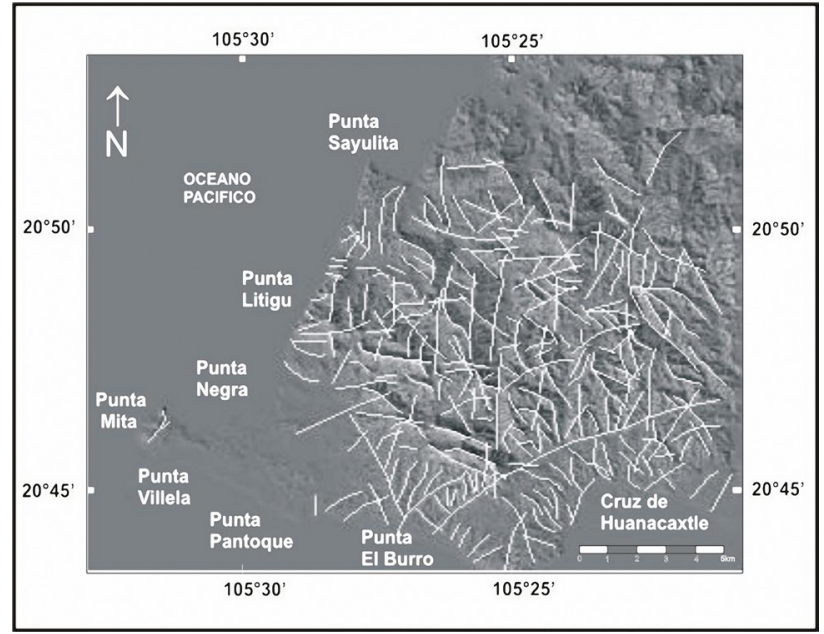

Figura 5. Superposición de los lineamientos identificados con el realce espacial aplicado al modelo digital del terreno y a las imágenes Landsat TM.

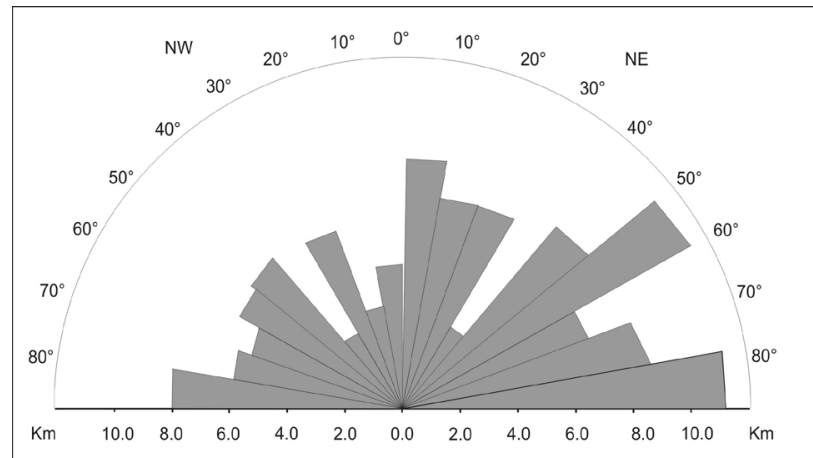

Figura 6. Diagrama de rosa obtenido a partir de los lineamientos identificados con las técnicas de realce espacial aplicadas al Modelo Digital de Elevación. (En el diagrama se han graficado los lineamientos en escala de longitud en lugar de frecuencia). Las direcciones preferenciales de los 151 lineamientos identificados se encuentran entre los $\mathrm{N} 0^{\circ}-10^{\circ} \mathrm{E} ; \mathrm{N}$ $40^{\circ}-50^{\circ} \mathrm{E} ; \mathrm{N} 70^{\circ}-80^{\circ} \mathrm{E}$ y $\operatorname{los} \mathrm{N} 40^{\circ}-60^{\circ} \mathrm{W}$.

\section{Resultados del realce espectral}

Para el realce espectral se utilizó un recorte de las seis bandas no térmicas de la imagen TM Landsat 5 (865 columnas, 668 renglones) del 23 de febrero de 1999. La fecha de toma de la imagen facilitó la identificación litológica por ser la temporada de secas, por lo tanto la cubierta vegetal del área era mínima y no causó una interferencia significativa con la respuesta espectral de las rocas.

En este caso se utilizó el Análisis de Componentes Principales Estandarizado (SPCA por sus siglas en inglés; Chávez y Kwarteng, 1989) para realzar y mapear las diferencias espectrales de cada tipo de cubierta. Se aplicaron los dos métodos que incluye esta técnica a las imágenes Landsat TM, siendo el segundo método, en el que se seleccionan pares de bandas que presentan menor correlación, el que proporciona mejores resultados para la discriminación de la litología. El análisis de componentes principales 
fue útil para resaltar los rasgos de las diferentes litologías debido a que se aplicó por pares de bandas, donde una de las componentes tenía la mayor parte de la información útil para diferenciar dos o tres tipos de roca, por eso este análisis se llevó a cabo en tres ocasiones, para los pares de bandas: TM2-TM7, TM4-TM7 y TM2-TM4. No se utilizaron métodos de clasificación supervisada para realizar el mapeo litológico, ya que la clasificación únicamente toma los valores de brillantez de los píxeles en las diferentes bandas y los asocia por su semejanza en el espacio espectral, por lo que si no se hace previamente una operación de realce, no se tienen en general buenos resultados para diferenciar varios tipos de cobertura.

Para seleccionar los pares de bandas que se emplearon en el análisis espectral, se examinó la matriz de correlación para todas las bandas (Tabla 1). Se seleccionaron los pares menos correlacionados: TM2-TM7 y TM4-TM7 $(0.783$ y 0.785 respectivamente) y el par TM2- TM4, el cual presentó el menor coeficiente de correlación (0.581). Entre menor es la correlación el contenido de información al analizar el par de bandas es mayor puesto que la información redundante es menor. A estos tres pares se les aplicó el Análisis de Componentes Principales Estandarizado con lo que se obtuvieron dos componentes principales, siendo la segunda componente de cada par en la que se concentra la mayor cantidad de información espectral única en cada banda. Esta información se identifica visualmente como variaciones de brillantez de los píxeles de las componentes resultantes. Los datos obtenidos, a partir del SPCA aplicado a las imágenes de satélite, fueron comparados con la información recopilada en campo y reportada por Prol-Ledesma y colaboradores (2003).

Se observa un mayor porcentaje de varianza en la Componente Principal 1 (CP1) del SPCA aplicado al par TM2-TM7 (Figura 7) por el aporte de información de la banda TM7, mientras que la Componente Principal 2 (CP2) presenta el mayor aporte de la banda TM2. Esto da como resultado que en la segunda componente principal se aprecien zonas oscuras bien delimitadas que corresponden a basaltos con alteración representada por óxidos de hierro en la porción de Punta Negra, y una zona de píxeles aún más oscuros en la parte correspondiente al depósito aluvial en la parte central de Punta de Mita hasta Punta Villela. En Cerro Calera y Cerro Pátzcuaro se identifica también una agrupación de píxeles con brillantez muy baja, esta zona corresponde en campo a un afloramiento de mármol. Una pequeña parte dentro de lo identificado como depósito aluvial, aparece en píxeles aún más obscuros que en campo corresponde a conglomerados de arenisca, lutita y limonita.

En el par TM4-TM7 (Figura 8) la primera componente principal recibe un porcentaje de varianza elevado en la banda TM7 por lo que la separación entre arenisca y basaltos se facilita. En la CP2 el mayor aporte lo hace la banda TM4, por lo que es posible identificar un afloramiento de la ignimbrita de composición riolítica en la línea de costa
Tabla 1 a) Coeficientes de correlación del par de bandas TM2-TM7.

\begin{tabular}{lll}
\hline Var/Covar & Mita2 & Mita7 \\
\hline Mita2 & 318.94 & 433.02 \\
Mita7 & 433.02 & 959.66 \\
Matriz Corr. & Mita 2 & Mita7 \\
Mita2 & 1.000000 & 0.782696 \\
Mita7 & 0.782696 & 1.000000 \\
Componente & $\mathbf{C 1}$ & $\mathbf{C 2}$ \\
\% Var. & 92.13 & 7.87 \\
Eigenval. & 1177.95 & 100.66 \\
eigenvec.1 & 0.450135 & 0.892960 \\
eigenvec.2 & 0.892960 & -0.450135 \\
Carga de bandas & $\mathbf{C 1}$ & $\mathbf{C 2}$ \\
Mita2 & 0.865070 & 0.501651 \\
Mita7 & 0.989317 & -0.145783 \\
\hline
\end{tabular}

Tabla 1 b) Coeficientes de correlación del par de bandas TM4-TM7.

\begin{tabular}{lll}
\hline Var/Covar & Mita4 & Mita7 \\
\hline Mita4 & 939.49 & 745.34 \\
Mita7 & 745.34 & 959.66 \\
Matriz Corr. & Mita4 & Mita7 \\
Mita4 & 1.00000 & 0.784959 \\
Mita7 & 0.784959 & 1.000000 \\
Componente & $\mathbf{C 1}$ & $\mathbf{C 2}$ \\
\% Var. & 89.25 & 10.75 \\
Eigenval. & 1694.98 & 204.17 \\
eigenvec.1 & 0.702306 & 0.711875 \\
eigenvec. 2 & 0.711875 & -0.702306 \\
Carga de bandas & $\mathbf{C 1}$ & $\mathbf{C 2}$ \\
Mita4 & 0.943328 & 0.331861 \\
Mita7 & 0.946078 & -0.323940 \\
\hline
\end{tabular}

Tabla 1 c) Coeficientes de correlación del par de bandas TM2-TM4

\begin{tabular}{lll}
\hline Var/Covar & Mita2 & Mita4 \\
\hline Mita4 & 318.94 & 317.92 \\
Mita7 & 317.92 & 939.49 \\
Matriz Corr. & Mita2 & Mita4 \\
Mita4 & 1.000000 & 0.580787 \\
Mita7 & 0.580787 & 1.000000 \\
Componente & $\mathbf{C 1}$ & $\mathbf{C 2}$ \\
\% Var. & 85.30 & 14.70 \\
Eigenval. & 1073.45 & 184.98 \\
eigenvec.1 & 0.388298 & 0.921534 \\
eigenvec.2 & 0.921534 & -0.388298 \\
Carga de bandas & $\mathbf{C 1}$ & $\mathbf{C 2}$ \\
Mita4 & 0.712363 & 0.701812 \\
Mita7 & 0.985045 & -0.172299 \\
\hline
\end{tabular}




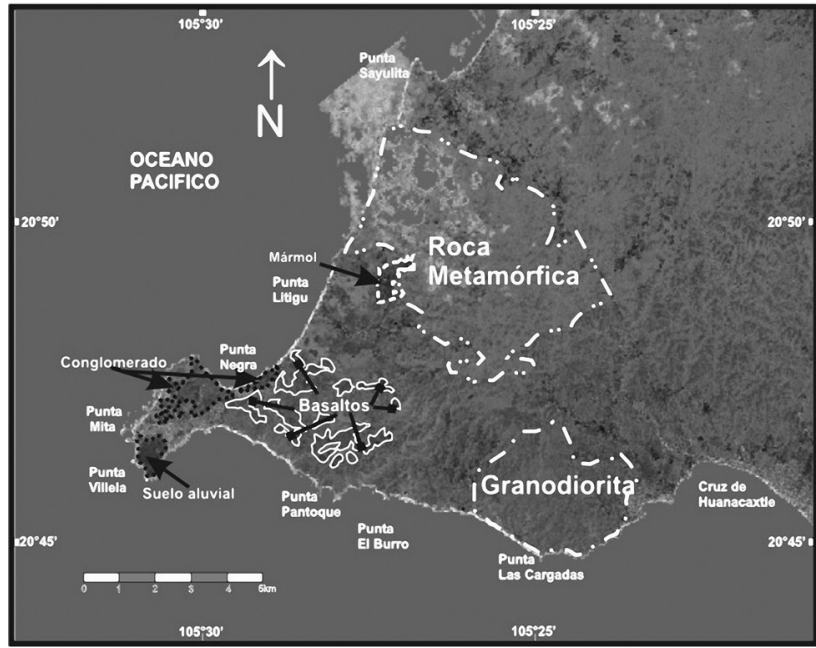

Figura 7. Componente Principal 2, resultado del ASCP del par TM 2-7. Esta imagen realza la respuesta espectral de basaltos, mármol, conglomerados y depósitos aluviales.

noroccidental de Punta de Mita en tonos grises más claros que el resto de la zona que lo rodea, la cual corresponde a basaltos según se identificó con los otros pares y que se verificó en campo. También en esta componente se identifican algunos derrames de lava. El afloramiento de un cuerpo intrusivo se identifica fácilmente con píxeles de tonos grises más obscuros que la roca metamórfica con la que hace contacto. Así mismo, la roca metamórfica muestra un mayor contraste con la porción formada por mármol, el cual se presenta en píxeles más claros y brillantes en esta componente.

El par TM2-TM4 (Figura 9) tiene un buen contraste espectral, lo que facilita la identificación de áreas de vegetación en tonos oscuros en la CP2. En la porción de Punta el Burro hasta Punta Pantoque, se observan conjuntos de píxeles obscuros que coinciden con flujos piroclásticos de composición basáltica. En la imagen se distingue un contraste entre estos píxeles y otros más claros, lo que indica un contacto que coincide con una secuencia de coladas o derrames constituidos por basaltos intercalados con areniscas, desde Punta Pantoque hasta el poblado Punta de Mita (Prol-Ledesma et al., 2003). Con este par es claramente visible una variación en el tono de los píxeles, lo que indica el contacto entre la roca metamórfica y el intrusivo de granodiorita.

\section{Integración de los resultados y conclusiones}

La comparación de los resultados obtenidos con el análisis de los lineamientos coincide con los datos recopilados en el campo (Prol-Ledesma et al., 2003). En el caso de la identificación de los afloramientos en campo y su relación con los resultados del realce espectral de las imágenes multiespectrales, se obtuvo una buena identificación de los contactos y permitió definir un mapa que proporciona

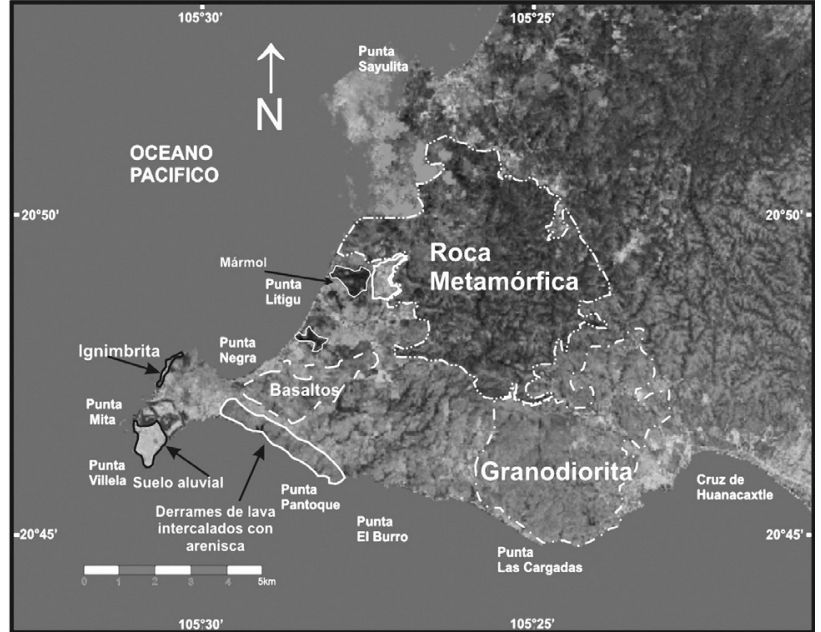

Figura 8. Componente Principal 2, resultado del ASCP del par TM 4-7. Esta componente resalta los afloramientos de ignimbrita, basaltos, granodiorita y las rocas metamórficas.

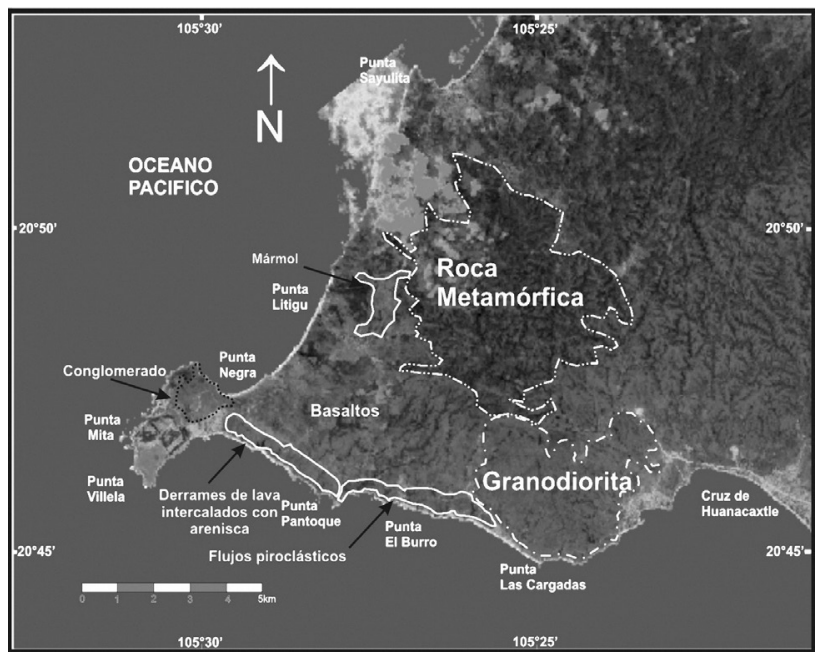

Figura 9. Componente Principal 2, resultado del ASCP del par TM 2-4. Esta componente resalta los flujos piroclásticos de composición basáltica, los basaltos intercalados con areniscas. También resalta el contacto entre el intrusivo granodiorítico y las rocas metamórficas.

información litológica a más detalle que los mapas disponibles de la zona de Punta Mita.

El resultado final de la aplicación del análisis morfológico y la aplicación de técnicas de realce digital se presenta en los mapas de la figura 10, en los que se muestran tanto las diferentes litologías identificadas con el realce espectral (Figura 10A), como los lineamientos (Figura 10B), por el análisis de componentes principales y la verificación de campo.

Las técnicas de realce espacial digital aplicadas a imágenes de satélite y al modelo digital de elevación facilitaron la identificación de un mayor número de lineamientos en comparación con el análisis morfo-hidrológico. Los resultados de la identificación de lineamientos indican que con el análisis del modelo digital del terreno se obtuvo un 

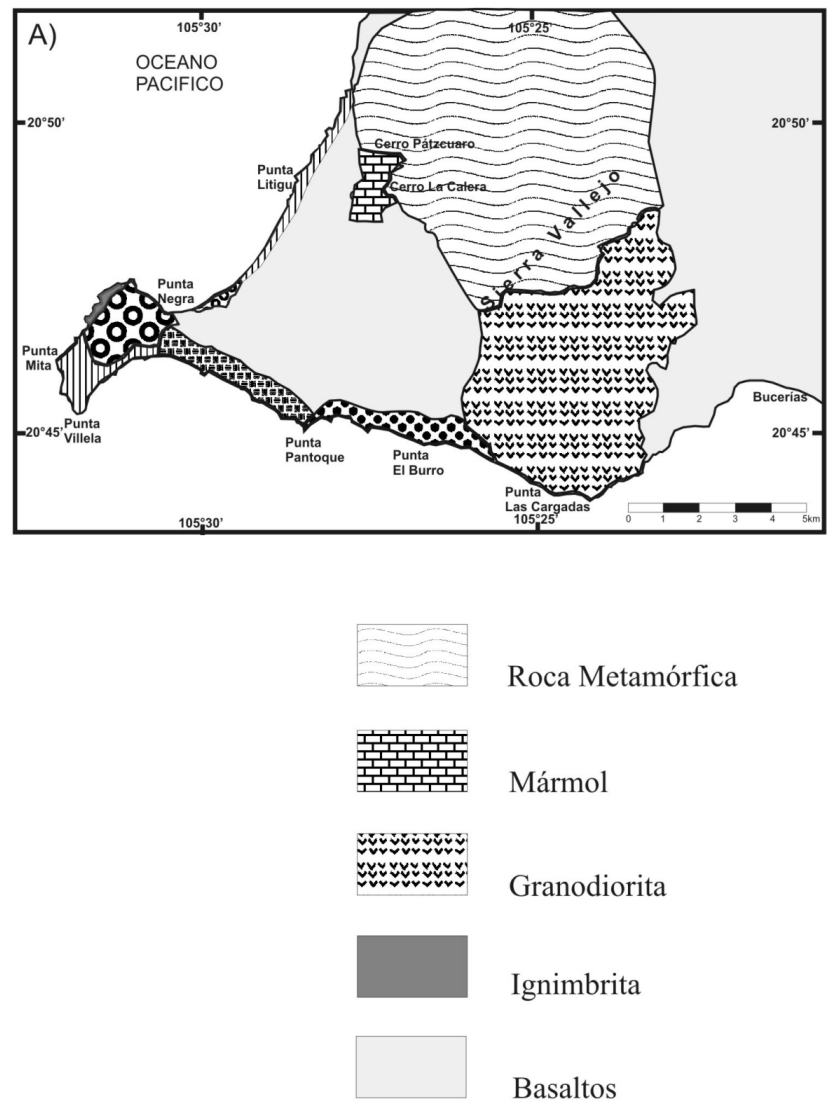

Roca Metamórfica

Mármol

Granodiorita

Ignimbrita

Basaltos
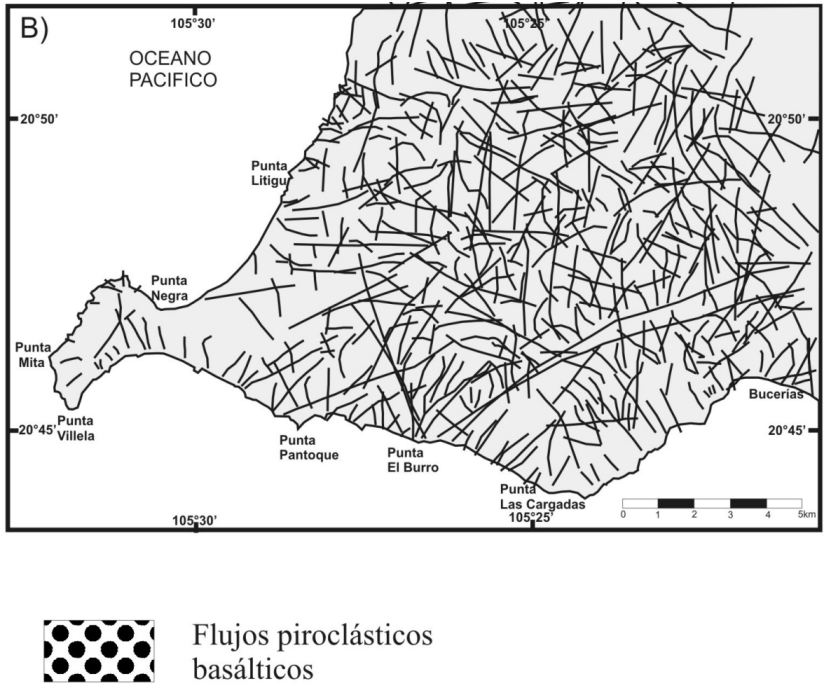

Flujos piroclásticos

basálticos

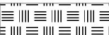

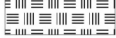

Derrames de basalto

intercalados con arenisca

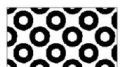

Conglomerado

Arena no consolidada

Lineamientos

Figura 10. Mapas que resumen los resultados del análisis espectral (A) y espacial (B) de las imágenes multiespectrales y del modelo digital del terreno de la zona de Punta Mita.

$26.3 \%$ más de lineamientos en comparación con el análisis morfológico de las imágenes multiespectrales realzadas espacialmente. Por otra parte, el ASCP facilitó la discriminación litológica al hacer evidentes las diferencias tonales entre píxeles, encontrando coincidencia con observaciones de campo reportadas para esa zona (Prol-Ledesma et al., 2003).

En todas las identificaciones de lineamientos, los predominantes corresponden a la fase de tectonismo de extensión en la zona, que es la más reciente y que origina el graben de Puerto Vallarta. Esta actividad es la que debe estar relacionada con el volcanismo basáltico de fisura observado a lo largo de toda la costa sur de Punta Mita y con la actividad hidrotermal submarina que se ha observado en esta zona a lo largo de fracturas que corresponden con el sistema $\mathrm{N} 30^{\circ}-40^{\circ} \mathrm{E}$, que es uno de los predominantes en el área. Estos resultados motivaron la búsqueda de otras manifestaciones submarinas ligadas con estructuras similares y en 2009 se descubrieron otras descargas gasohidrotermales en una estructura paralela a la estudiada a aproximadamente $200 \mathrm{~m}$ de las ventilas submarinas que habían sido estudiadas, lo cual confirma la relación de la actividad hidrotermal con la presencia del sistema de fracturas $\mathrm{N} 30^{\circ}-40^{\circ} \mathrm{E}$.

\section{Agradecimientos}

Este proyecto contó con el apoyo de CONACyT SEP2004-C01-46172 y CONACyT 32510-T. Los autores agradecen a dos revisores anónimos, cuyas observaciones fueron de gran utilidad para mejorar la calidad de este trabajo.

\section{Referencias}

Chávez, P.S. Jr., Kwarteng, Y.A., 1989, Extracting spectral contrast in Landsat Thematic Mapper image data using Selective Principal Component Analysis: Photogrammetric Engineering \& Remote Sensing, 55, 339-348.

Ferrari, L., Pasquarè, G., Venegas, S., Castillo, D., Romero, F., 1994, Regional tectonics of western Mexico and its implications for the northern boundary of the Jalisco block: Geofísica Internacional, $33,1,139-151$.

Ferrari, L., López-Martínez, M., Aguirre-Diaz, G., Carrasco-Núñez, G., 1999, Space-time patterns of Cenozoic arc volcanism in central Mexico: From the Sierra Madre Occidental to the Mexican Volcanic Belt: Geology, 27, 4, 303-306.

Ferrari, L., Conticelli, S., Vagelli, G., Petrone, C.M., Manneti, P., 2000, Late Miocene volcanism and intra-arc tectonics during the early development of the Trans-Mexican Volcanic Belt: Tectonophysics, $318,161-185$. 
Gastil, G., Krummenacher, D., Minch, J., 1979, The record of Cenozoic volcanism around the Gulf of California: Geological Society of America Bulletin, 90, 839-857.

Helenes, J., Carreño, A.L., 1999, Neogene sedimentary evolution of Baja California in relation to regional tectonics: Journal of South American Earth Sciences, 12, 589-605.

Mustard, J.F., Sunshine, J.M., 1999, Spectral analysis for Earth Science: investigations using remote sensing data, in Rencz, A.N. (ed.), Remote Sensing for the Earth Sciences: Manual of Remote Sensing: New York, John Wiley \& Sons, 251-306.

Núñez-Cornú, F.J., Prol-Ledesma, R.M., Cupul-Magaña, A., SuárezPlascencia, C., 2000, Near-shore submarine hydrothermal activity in Bahía de Banderas, western Mexico: Geofísica Internacional, 39, 171-178.

Prol-Ledesma, R.M., Canet, C., Tolson, G., García-Palomo, A., Miller, R., Rubio-Ramos, M.A., Torres-de León, R., Huicochea-Alejo, J.S., 2003, Basaltic volcanism and submarine hydrothermal activity in Punta Mita, Nayarit, Mexico, in Geologic transects across Cordilleran Mexico, Guidebook for the field trips of the 99th Geological Society of America Cordilleran Section Annual Meeting: México, D.F., Universidad Nacional Autónoma de México, Instituto de Geología, Publicación Especial 1, 169-182.

Ramírez, M.T., 2002, Holocene coastal uplift along Punta de Mita, the Pacific margin of southwest Mexico, in Leroy, S., Stewart, I.S. (eds.), Environmental catastrophes and recovery in the Holocene (abstracts volume): West London, UK, Department of Geography and Earth Sciences - Brunel University, 67.

Ruíz-Armenta, J.R., Prol-Ledesma, R.M., 1995, Técnicas de procesamiento de imágenes en la exploración de yacimientos minerales de origen hidrotermal: Física de la Tierra, 7, 105-137.
Schaaf, P., 1990, Isotopengeochemische untersuchungen an granitoiden Gesteinen eines aktiven Kontinentalrandes: Alter und Herkunft del Tiefengesteinskomplexe an der Pazifikkuste Mexikos zwischen Puerto Vallarta und Acapulco: Munich, Bavaria, Alemania, Universidad de Munich, Tesis doctoral, $202 \mathrm{p}$.

Schaaf, P., Köhler, H., Müller-Sohnius, D., von Drach, V., 1993, Puerto Vallarta Batholith - its anatomy displayed by isotopic fine structure (resumen), in Proceedings of the First Circum-Pacific and CircumAtlantic Terrane Conference: México, D.F., Instituto de Geología - UNAM, 133-135.

Schaaf, P., Böhnel, H., Pérez-Venzor, J.A., 2000, Pre-Miocene palaeogeography of the Los Cabos block, Baja California Sur: Tectonophysics, 318, 53-69.

Sedlock, R.L., Ortega-Gutierrez, F., Speed, R.C., 1993, Tectono-stratigraphic terranes and tectonic evolution of México: Geological Society of America Special Paper 278, 153 p.

Süzen, M.L., Toprak, V., 1998, Filtering of satellite images in geological lineament analyses: an application to a fault zone in Central Turkey: International Journal of Remote Sensing, 19, 1101-1114.

Wallace, P., Charmichael, I.S.E., Ritghter, K., Becker, T.A., 1992, Volcanism and tectonism in western Mexico: A contrast of style and substance: Geology, 20, 625-628.

Wester, K., Lunden, B., 1996, Digital elevation data, Landsat TM and magnetic data for visualization of geomorphological and geological features, in Singhroy, V.H., Nebert, D.D., Johnson, A.I. (eds.), Remote sensing and GIS for site characterization: applications and standards: West Conshohocken, Pennsylvania, USA, American Society for Testing and Materials, 29-37.

Zumsprekel, H., Prinz, T., 2000, Computer-enhanced multispectral remote sensing data: a useful tool for the geological mapping of Archean terrains in (semi)arid environments: Computers \& Geosciences, 26, 87-100.

Manuscrito recibido: Octubre 08, 2009

Manuscrito corregido recibido: Febrero 05, 2010

Manuscrito aceptado: Febrero 10, 2010 